\title{
Examination of the Two Types of ENSO in the NCEP CFS Model and Its Extratropical Associations
}

\author{
SEON TAE KIM AND Jin-Yi YU \\ Department of Earth System Science, University of California, Irvine, Irvine, California
}

ARUN KUMAR

NOAA/NCEP/Climate Prediction Center, Camp Springs, Maryland

HUI WANG

NOAA/NCEP/Climate Prediction Center, Camp Springs, Maryland, and Wyle Information Systems, McLean, Virginia

(Manuscript received 21 October 2011, in final form 29 November 2011)

\begin{abstract}
Two types of El Niño-Southern Oscillation (ENSO) simulated by the National Centers for Environmental Prediction (NCEP) Climate Forecast System (CFS) model are examined. The model is found to produce both the eastern Pacific (EP) and central Pacific (CP) types of ENSO with spatial patterns and temporal evolutions similar to the observed. The simulated ENSO intensity is comparable to the observed for the EP type, but weaker than the observed for the CP type. Further analyses reveal that the generation of the simulated $\mathrm{CP}$ ENSO is linked to extratropical forcing associated with the North Pacific Oscillation (NPO) and that the model is capable of simulating the coupled air-sea processes in the subtropical Pacific that slowly spreads the NPO-induced SST variability into the tropics, as shown in the observations. The simulated NPO, however, does not extend as far into the deep tropics as it does in the observations and the coupling in the model is not sustained as long as it is in the observations. As a result, the extratropical forcing of tropical central Pacific SST variability in the CFS model is weaker than in the observations. An additional analysis with the Bjerknes stability index indicates that the weaker CP ENSO in the CFS model is also partially due to unrealistically weak zonal advective feedback in the equatorial Pacific. These model deficiencies appear to be related to an underestimation in the amount of the marine stratus clouds off the North American coasts inducing an ocean surface warm bias in the eastern Pacific. This study suggests that a realistic simulation of these marine stratus clouds can be important for the CP ENSO simulation.
\end{abstract}

\section{Introduction}

Recent studies have suggested that two different types of interannual sea surface temperature (SST) variability can be observed in the tropical Pacific (Larkin and Harrison 2005a; Yu and Kao 2007; Ashok et al. 2007; Kao and Yu 2009; Kug et al. 2009). One type has its SST anomalies centered in the eastern Pacific and has been considered as the conventional type of El Niño-Southern Oscillation (ENSO; Rasmusson and Carpenter 1982). The other type has its SST anomalies confined within the central Pacific. Kao and Yu (2009) termed these two

Corresponding author address: Jin-Yi Yu, Department of Earth System Science, University of California, Irvine, Irvine, CA 92620. E-mail: jyyu@uci.edu types as the eastern Pacific (EP) and central Pacific (CP) types of ENSO, respectively. Different terms are also used to describe the type of warming events similar to the $\mathrm{CP}$ ENSO discussed here, including "date line El Niño" (Larkin and Harrison 2005a), "El Niño Modoki" (Ashok et al. 2007), and "warm pool El Niño" (Kug et al. 2009).

The CP type of ENSO has been suggested to produce different climate impacts from the conventional EP type (e.g., Larkin and Harrison 2005a,b; Kao and Yu 2009; Weng et al. 2009; Kim et al. 2009; Yeh et al. 2009; Mo 2010). By examining subsurface ocean temperature variations, Kao and Yu (2009) discovered that basin-wide thermocline variations appear in the evolution of the EP ENSO, but not in the CP ENSO. The latter relies more on local air-sea interactions in the central equatorial Pacific. This suggestion was further supported by $\mathrm{Yu}$ and 
Kim (2010a), who analyzed observed CP El Niño events since the 1960s to show that CP El Niño events can occur during times when the mean thermocline depth along the equatorial Pacific is above, below, or near normal, and does not show a consistent behavior. These studies suggested that the generation of the CP ENSO does not rely on the thermocline variations necessary for the delayed oscillator (Schopf and Suarez 1988; Suarez and Schopf 1988; Battisti and Hirst 1989) or the recharge oscillator (Jin 1997). Kug et al. (2009) argued that zonal ocean advection is crucial to the development of the CP El Niño. Yu et al. (2010) emphasized that the zonal advection process becomes important after SST anomalies are excited at the equator by forcing associated with sea level pressure (SLP) variations in the extratropics. Yu and Kim (2011a) further showed that these extratropical SLP variations are mostly associated with the North Pacific Oscillation (NPO; Walker and Bliss 1932; Rogers 1981), which is characterized by a SLP anomaly dipole between a subpolar low and subtropical high. Yu and Kim (2011a) argued that the CP ENSO is an extratropically excited mode of the tropical Pacific variability.

Because of the limited observational record, extended simulations produced by the state-of-the-art coupled models have been used to further explore the dynamics of the CP ENSO and the robustness of the mechanisms for its generation. Yu and Kim (2010b) examined the preindustrial simulations produced by World Climate Research Programme's Coupled Model Intercomparison Project phase 3 (CMIP3) models to show that 6 of the 19 coupled models simulate realistically strong EP and CP types. Kug et al. (2010) analyzed the simulation produced by the Geophysical Fluid Dynamics Laboratory (GFDL) Coupled Model version 2.1 (CM2.1) to confirm the important role of zonal advective feedback in the development of the CP El Niño. A major coupled climate model not included in the CMIP3 analysis is the global coupled atmosphere-ocean Climate Forecast System (CFS) model developed at the National Centers for Environmental Prediction (NCEP), which is used for operational seasonal climate prediction. The performance of this model in ENSO simulations has been documented and examined by several studies. Wang et al. (2005), for example, showed that the model is capable of simulating ENSO events similar to those observed in terms of intensity, phase locking, and spatial pattern, although the simulated ENSO occurs too regularly. Zhang et al. (2007) performed a mixed layer heat budget analysis to show that the main ENSO dynamics in the CFS model can be explained by the revised conceptual recharge-discharge oscillator of Jin and An (1999), in that both the thermocline feedback and zonal advective feedback are involved in the simulated ENSO development. However, the concept of different types of ENSO was not considered in these studies.

It is not known how well the different types, particularly the CP type of ENSO, are simulated by the CFS model. Such an analysis is important in the context of seasonal climate predictions. For example, Hendon et al. (2009) showed that a model's ability to predict ENSO impacts on climate depends on whether the model can simulate both types of ENSO. In addition, Sun and Yu (2009) argued that the existence of both the EP and CP ENSOs allows ENSO to slowly modify the tropical Pacific mean state through an ENSO-tropical Pacific interaction mechanism. Yu and Kim (2011b) analyzed CMIP3's preindustrial simulations to confirm that models capable of simulating both the EP and CP ENSO tend to produce stronger decadal ENSO modulations. Therefore, identifying the realism of the two types of ENSO simulated in the CFS model can also be important for further understanding and improving seasonal or even decadal climate predictions.

In this study, we examine the properties of the EP and CP types of ENSO produced by the CFS model, with particular emphasis on the CP ENSO and its association with extratropical atmospheric variations. In section 2 , the model output and data used in the study are described. Section 3 examines the two types of ENSO in the CFS model. In section 4, we examine the roles of extratropical forcing and zonal advective feedback in generating the CP-type ENSO in the CFS model and compare them to those in the observations. A summary and discussion is presented in section 5 .

\section{Model and data}

In this study, a 500-yr preindustrial simulation produced by the CFS is analyzed. The model consists of the atmospheric component of the NCEP Global Forecast System (GFS) model and the GFDL Modular Ocean Model version 3 (MOM3; Pacanowski and Griffies 1998). The atmospheric model (GFS) uses a triangular horizontal spectral truncation of 62 waves and has 64 vertical levels. The MOM3 ocean model has horizontal domain extending from $74^{\circ} \mathrm{S}$ to $64^{\circ} \mathrm{N}$ with a longitudinal resolution of $1^{\circ}$ and a latitudinal resolution of $1 / 3^{\circ}$ between $10^{\circ} \mathrm{S}$ and $10^{\circ} \mathrm{N}$, which gradually increases through the tropics until becoming a fixed $1^{\circ}$ resolution poleward of $30^{\circ} \mathrm{S}$ and $30^{\circ} \mathrm{N}$. The ocean model has 40 layers in the vertical with a 10-m resolution in the upper $240 \mathrm{~m}$.

During the coupled run, which is performed without flux correction, the two components exchange daily averaged quantities once a day. Since latitudinal domain is different, full interaction between atmospheric and 

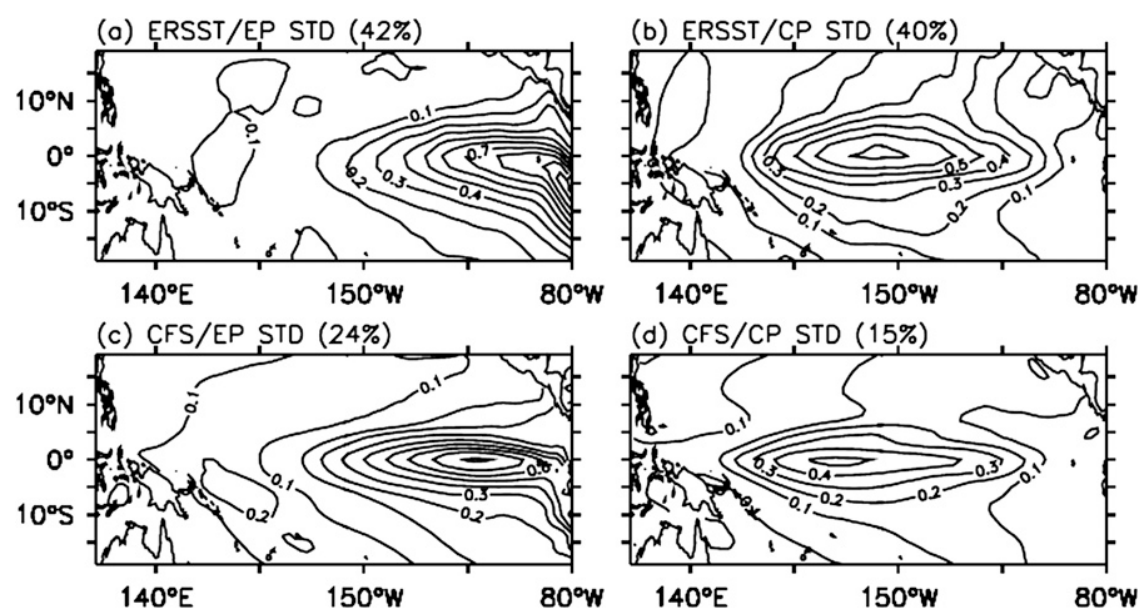

FIG. 1. Spatial patterns of standard deviations $\left(\mathrm{STD} ;{ }^{\circ} \mathrm{C}\right)$ of the first EOF mode for the (left) EP ENSO and (right) CP ENSO calculated from the (a),(b) observations and (c),(d) CFS model. The percentage of variance explained by the first EOF mode is also shown in parentheses.

oceanic components occurs within $65^{\circ} \mathrm{S}-50^{\circ} \mathrm{N}$. Poleward of $74^{\circ} \mathrm{S}$ and $64^{\circ} \mathrm{N}$, SSTs for the atmospheric component are taken from observed seasonally varying climatology. Between $74^{\circ}$ and $65^{\circ} \mathrm{S}$, and between $64^{\circ}$ and $50^{\circ} \mathrm{N}$, SSTs for the atmospheric component are the weighted average of the observed climatology and that simulated by the ocean component of CFS, with the weight linearly varying in latitude. The weights are such that the SSTs at $74^{\circ} \mathrm{S}$ and $64^{\circ} \mathrm{N}$ equal observed climatology, and at $65^{\circ} \mathrm{S}-$ $50^{\circ} \mathrm{N}$ the SSTs equal values from the ocean component of the CFS. Sea ice extent is prescribed from the observed climatology. A more detailed description of the CFS model can be found in Wang et al. (2005).

Several observational datasets are used in this study for comparisons. For SST, we use the National Oceanic and Atmospheric Administration (NOAA) Extended Reconstruction of Historical Sea Surface Temperature version 3 (ERSSTv3) data (Smith and Reynolds 2003) from the National Climatic Data Center (NCDC). For the SLP and surface winds, we use the NCEP-National Center for Atmospheric Research (NCAR) reanalysis (Kistler et al. 2001) data. Subsurface ocean temperature and zonal and vertical velocities are taken from the Simple Ocean Data Assimilation (SODA; Carton and Giese 2008) reanalysis. In this study, we choose to analyze the observations for the period 1950-2010, except for the SODA data where the period 1950-2008 was used. For both the CFS simulation and the observations, anomalies were computed by removing the monthly-mean climatology and the trend.

\section{Two types of ENSO in the CFS}

Kao and Yu (2009) argued that the EP and CP types have different generation mechanisms and can coexist to contribute to the tropical Pacific SST anomalies, and that contrasting SST anomalies in specific regions of the Pacific cannot fully separate the two types. Instead, they used a regression method to separate the SST anomalies into the components associated separately with the EP and $\mathrm{CP}$ types and then applied an empirical orthogonal function (EOF) analysis to each of the components to obtain the leading spatial patterns of these two types. They then projected tropical Pacific SST anomalies onto these two EOF patterns to determine the ENSO type. The same combined regression-EOF analysis is applied in this study to identify the CP and EP types of ENSO in the CFS model and observations.

To obtain the CP ENSO structure with the EOF analysis, we first subtracted the anomalies regressed with the Niño-1+2 index from the total SST anomalies before the EOF analysis was applied. Here the regression with the Niño- $1+2$ index is considered as an estimate of the influence of the EP ENSO, which should be removed to better reveal the SST anomalies associated with the CP ENSO. Similarly, we subtracted the SST anomalies regressed with the Niño-4 index (i.e., representing the influence of the CP ENSO) from the total SST anomalies before the EOF analysis was applied to identify the leading structure of the EP ENSO. In contrast to Kao and $\mathrm{Yu}$ (2009), we remove not only the simultaneous regression, but also the regressions at lags $\pm 1, \pm 2, \pm 3$, and \pm 4 months using a linear multiple regression method to avoid the propagation of SST anomalies. Principal components (PC) of the leading EOF modes for the CP and EP ENSOs are defined, respectively, as the CP index and the EP index.

Figure 1 shows the leading EOF modes obtained from the ERSSTv3 and the CFS simulation. In the observations 

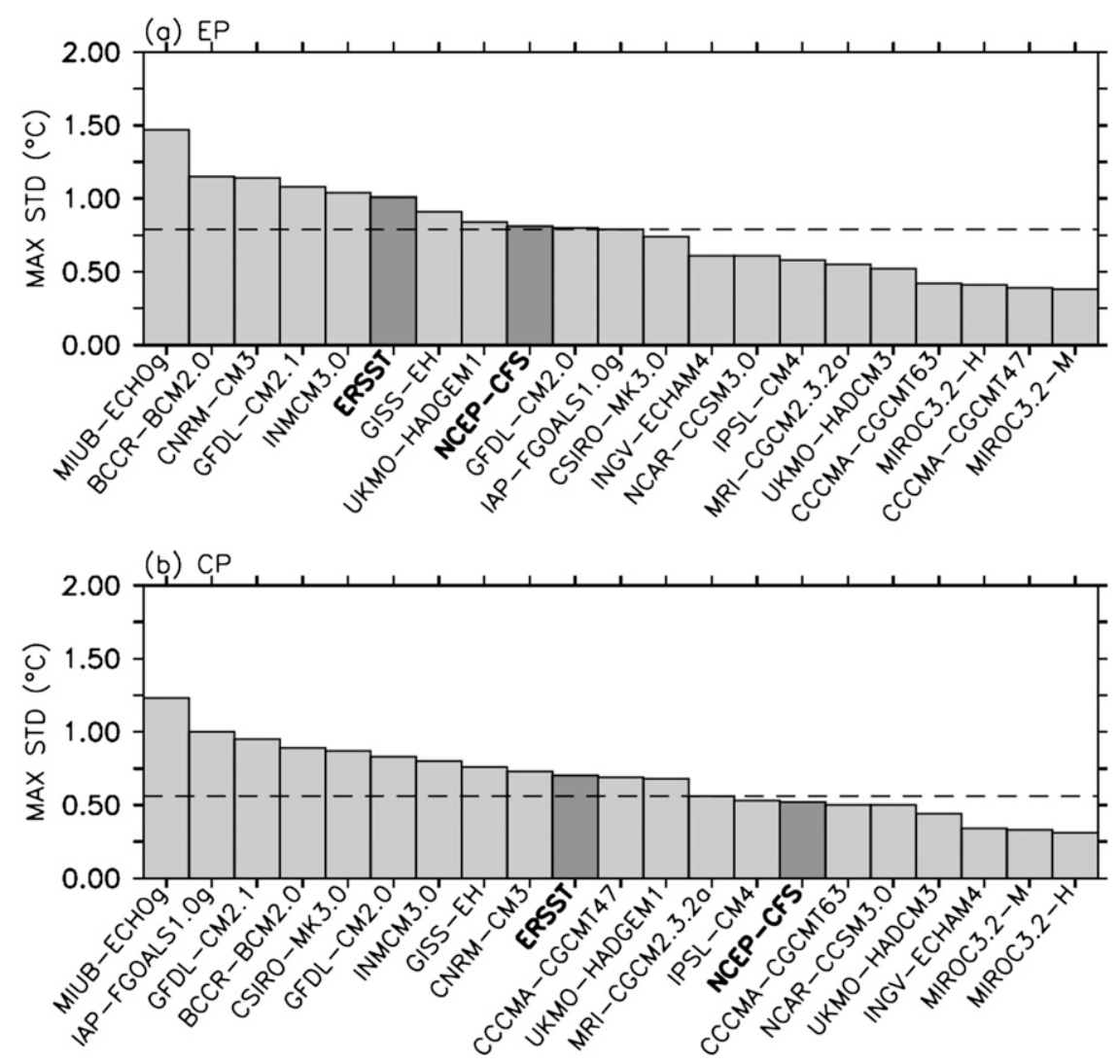

FIG. 2. Bar charts of maximum STD for (a) EP and (b) CP ENSO from models and observations. The maximum STD for the CFS model and observations is estimated between $10^{\circ} \mathrm{N}$ and $10^{\circ} \mathrm{S}$ in Fig. 1. The maximum STDs from the CMIP3 models are taken from Yu and Kim (2010b). The lower limit of the $95 \%$ significance interval of the observed STD (dashed line) is estimated from the observations and CFS model based on an $f$ test.

(Figs. 1a,b), the EP ENSO is characterized by SST anomalies extending from the South American coast into the central equatorial Pacific. The observed CP ENSO is characterized by SST anomalies in the central tropical Pacific that extend toward the northern extratropical Pacific. In the CFS simulation (Figs. 1c,d), the SST anomaly patterns of the EP and CP ENSOs closely resemble the observations. The pattern correlation between the simulated and observed EOF modes is 0.94 for both the CP and EP types, although the simulated ENSOs are shifted by about $30^{\circ}$ to the west relative to the observed ones. The maximum SST variability simulated by the CFS for the EP ENSO is located at $115^{\circ} \mathrm{W}$, instead of immediately off the coast as in the observations; however, the southward extension of SST variability along the South American coast is well captured in the model. For the CP ENSO, the northeastward extension of the SST variability is weaker in the CFS model than in the observations.

In Fig. 1, the loading coefficients for the EOFs have been scaled by the square root of their corresponding eigenvalues to represent the standard deviations (STD) of each of the EOF modes. The maximum STD values are considered to represent the intensities of each type of ENSO. To further compare the performance of the CFS model with the observations and other coupled climate models, the maximum STD values are shown in Fig. 2 for the EP and CP EOFs calculated from the CFS model, 19 CMIP3 models, and the observations, ranked from the largest to the lowest values. The 19 CMIP3 models used here and their leading EOF modes for the $\mathrm{EP}$ and CP ENSOs were described and shown in $\mathrm{Yu}$ and Kim (2010b).

The observed intensities (i.e., the maximum STD) are $1.0^{\circ} \mathrm{C}$ for the EP ENSO and $0.73^{\circ} \mathrm{C}$ for the CP ENSO as shown in Fig. 2. The ratio of the EP to CP ENSO intensity is about 1.4, which means the EP ENSO is about $40 \%$ stronger than the CP ENSO. Following Yu and Kim (2010b), the lower limit of the 95\% significance interval of the observed ENSO intensities, according to an $f$ test, is used as the criteria to determine if the CFS model produces realistically strong ENSO intensities. 
The lower $95 \%$ limit values are $0.79^{\circ} \mathrm{C}$ for the EP type and $0.56^{\circ} \mathrm{C}$ for the $\mathrm{CP}$ type, and are indicated by the dashed lines in Fig. 2. Based on these criteria, the CFS produces a realistically strong EP type of ENSO (about $0.81^{\circ} \mathrm{C}$ ). However, the CFS does not simulate a realistically strong CP type of ENSO, as its intensity $\left(0.52^{\circ} \mathrm{C}\right)$ does not pass the lower limit threshold. Compared to the 19 CMIP3 models, the CFS model falls into the bottom $35 \%$ group of the models in terms of intensity of the simulated CP ENSO. The ratio of the EP to CP ENSO intensity in the CFS model is 1.6, which is larger than the observed ratio.

The lead-lag regressions of SST anomalies on the EP and CP indices are shown in Figs. 3 and 4, respectively, to compare the temporal evolution of the observed and simulated EP and CP ENSOs. In the observations (Fig. 3a), the warming during an EP ENSO starts near the South American coastal region (lags -15 to -12 ), then extends northward toward the equatorial cold tongue (lag -9), and eventually spreads zonally into the central equatorial Pacific (lags -6 to 0 ). After the EP index peaks, the EP ENSO decays as warming retreats backward toward the cold tongue region (lags +3 to +6 ). For the simulated EP ENSO (Fig. 3b), its development and decay are very similar to the observations.

As for the CP ENSO, the observed SST warming (Fig. 4a) appears first in the northeast subtropical Pacific (lag -15$)$, then extends into the central equatorial $\mathrm{Pa}-$ cific (lags -12 to -9 ). After SST anomalies are established at the equator, the warming intensifies rapidly with the anomalies extending eastward but remaining detached from the South American coast (lags -9 to 0$)$. The warming then decays locally in the central equatorial Pacific (lags +3 to +6 ). The simulated $\mathrm{CP}$ ENSO (Fig. 4b) shows all major evolution features of the observed one. Specifically, the simulated CP ENSO shows a meridional connection with the warming in the northeastern subtropical Pacific. However, one can also notice that the meridional extension appears weaker in the CFS simulation than in the observations. We will come back to this point later. Here, to further demonstrate the realism of the combined regression-EOF method, we show in Fig. 5 the evolution of two specific EP and CP El Niño events from the CFS simulations. The figure shows that their SST anomaly patterns are indeed similar to those (i.e., Figs. $3 b$ and $4 b$ ) regressed with $\mathrm{CP}$ and $\mathrm{EP}$ indices obtained by the combined regression-EOF method.

We examine the subsurface signatures of the simulated EP and CP ENSOs in Fig. 6. The vertical cross sections shown here are the lead-lag regression of subsurface ocean temperature anomalies along the equatorial Pacific (averaged between $5^{\circ} \mathrm{S}$ and $5^{\circ} \mathrm{N}$ ) onto the
EP and CP indices. The subsurface temperature anomalies in the CFS model are similar to the observed evolution reported in Kao and $\mathrm{Yu}$ (2009, see their Fig. 8 for the observed features). For the simulated EP ENSO (Fig. 6a), a basin-wide propagation associated with downwelling (warm subsurface temperature signatures from lags -14 to -9 ) or upwelling (cold subsurface temperature signatures from lags -3 to +11 ) Kelvin waves characterizes the evolution of the subsurface temperature anomalies, which appears first underneath the western Pacific warm pool and propagates eastward toward the cold tongue along the mean thermocline depth (i.e., the black line). This evolution is consistent with the subsurface ocean processes described by the delayed oscillator or recharge oscillator. In contrast, the subsurface temperature evolution of the simulated CP ENSO (Fig. 6b) does not involve much of basin-wide propagation. The subsurface temperature anomalies, instead, are confined within a shallow layer above the local mean thermocline in the western to central tropical Pacific and develop and decay in situ. Therefore, the CFS model simulates a realistic subsurface evolution for both the EP and CP ENSOs.

Figures 1-6, together, indicate that the CFS model simulates the EP ENSO with realistic patterns, evolution, and intensity, and suggest that the model likely captures well the thermocline dynamics responsible for the generation of the EP ENSO. On the other hand, the simulated CP ENSO in the CFS model has realistic spatial patterns, temporal evolution, and subsurface signatures, but its intensity is weaker than the observed. Therefore, it is likely that the model also captures the generation mechanism for the CP ENSO, but the mechanism does not operate as strongly or efficiently as in the observations. Since Yu et al. (2010) and Yu and Kim (2011a) suggested that extratropical SLP forcing is important for the CP ENSO generation, we next examine the extratropical associations of the CP ENSO in the CFS model and compare them with the observations.

\section{Extratropical associations of the simulated CP ENSO}

To explore the linkage of extratropical atmospheric forcing to the CP ENSO, we examine the leading EOF modes of interannual SLP anomalies over the extratropical Pacific. To isolate the leading patterns of interannual SLP variations in the subtropical and extratropical Pacific, the EOF analysis is applied to monthly SLP anomalies in a region between $20^{\circ}-60^{\circ} \mathrm{N}$ and $120^{\circ} \mathrm{E}-$ $80^{\circ} \mathrm{W}$. The analysis is applied to the CFS simulation and the NCEP-NCAR reanalysis. After obtaining the leading EOFs, we regress SLP anomalies from $20^{\circ} \mathrm{S}$ to $60^{\circ} \mathrm{N}$ 
(a) OBS
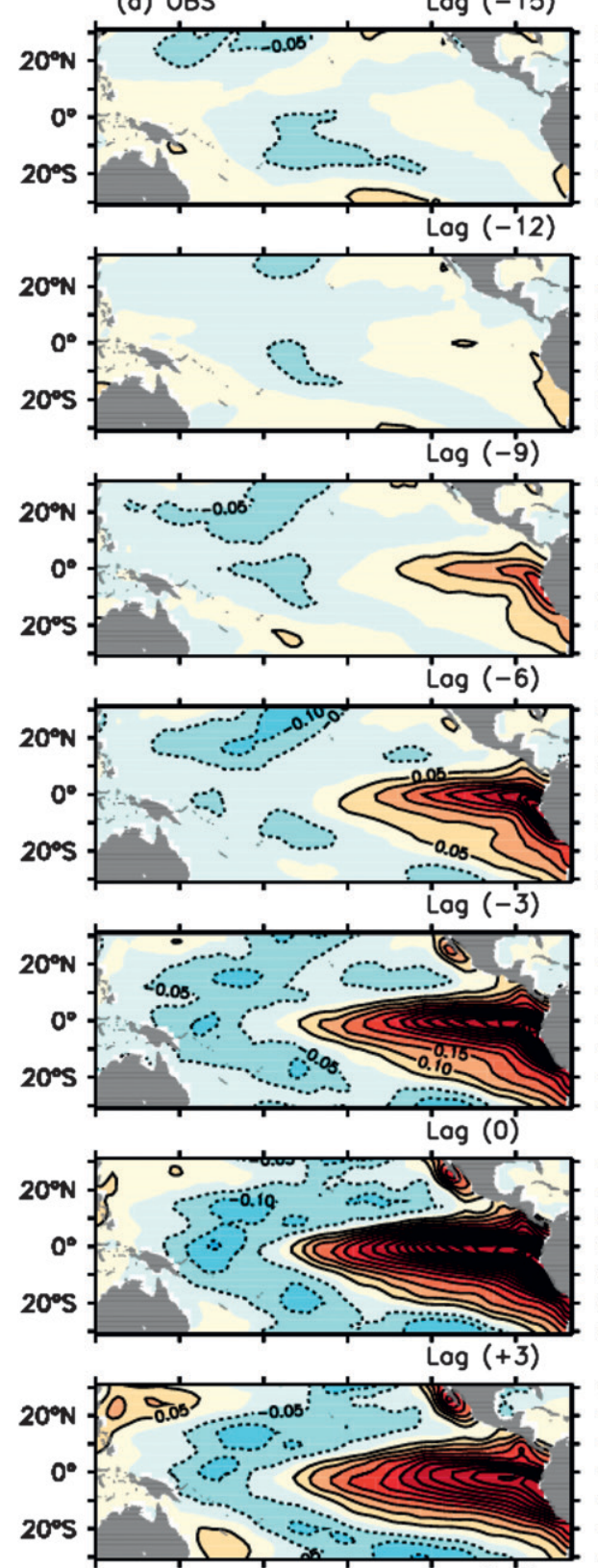

Log $(+6)$

$120^{\circ} \mathrm{E}$

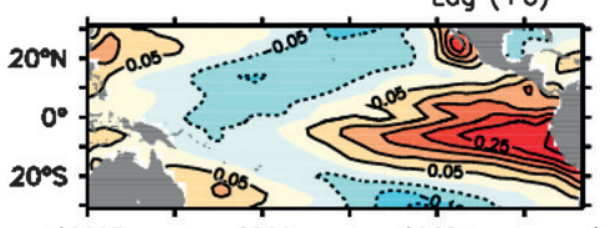

(b) CFS
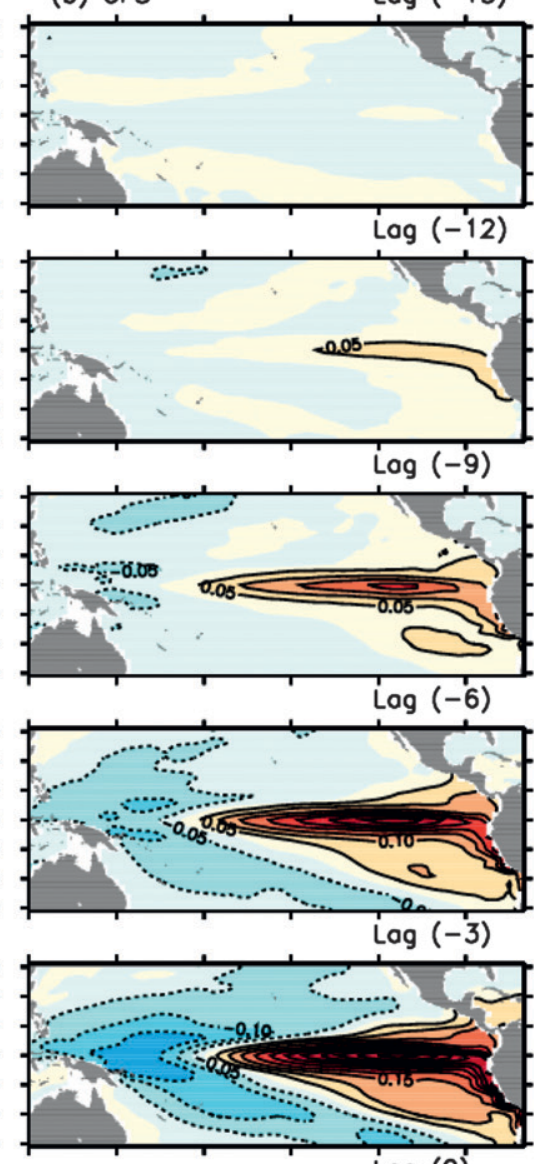

Log (0)
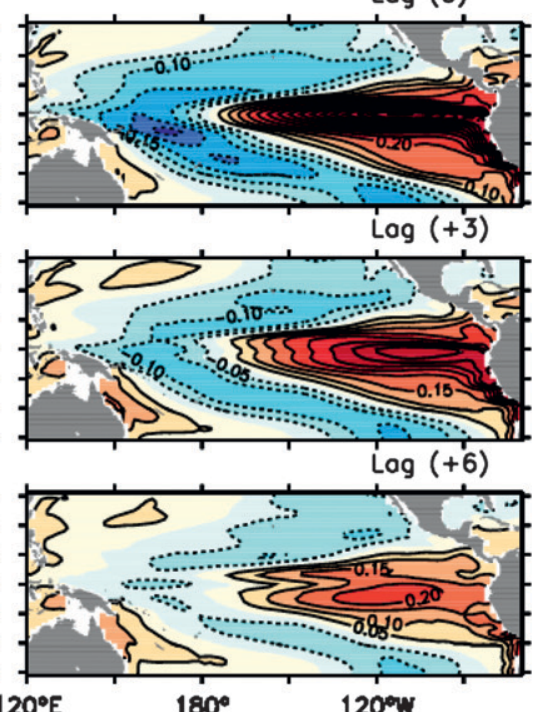

FIG. 3. Spatial patterns of the lead-lag regressions of SST anomalies onto the EP indices from (a) observations and (b) CFS model simulations. Positive lags indicate that the EP index leads SST anomalies. The zero contour lines are removed. 
(a) OBS
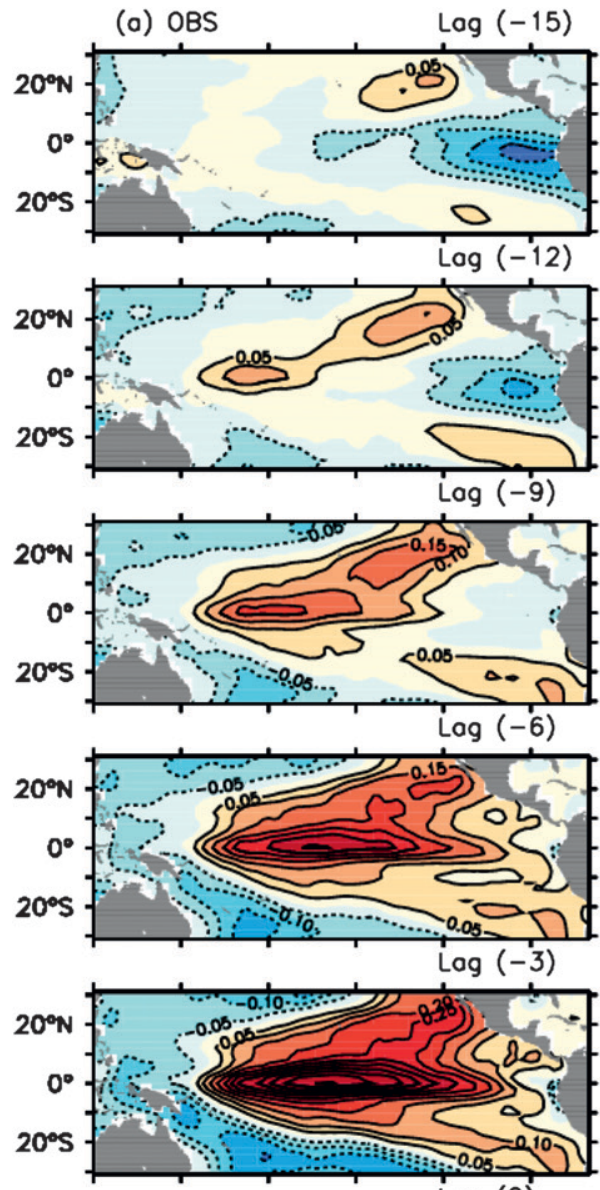
Log (0)

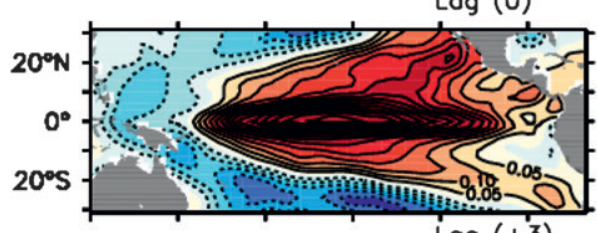
$\log (+3)$
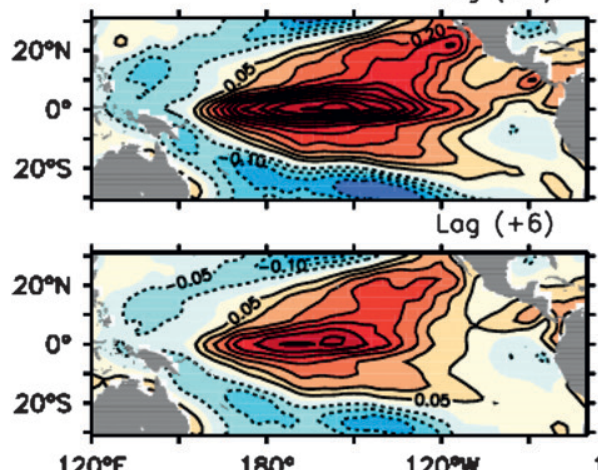

FIG. 4. As in Fig. 3, but for the CP indices
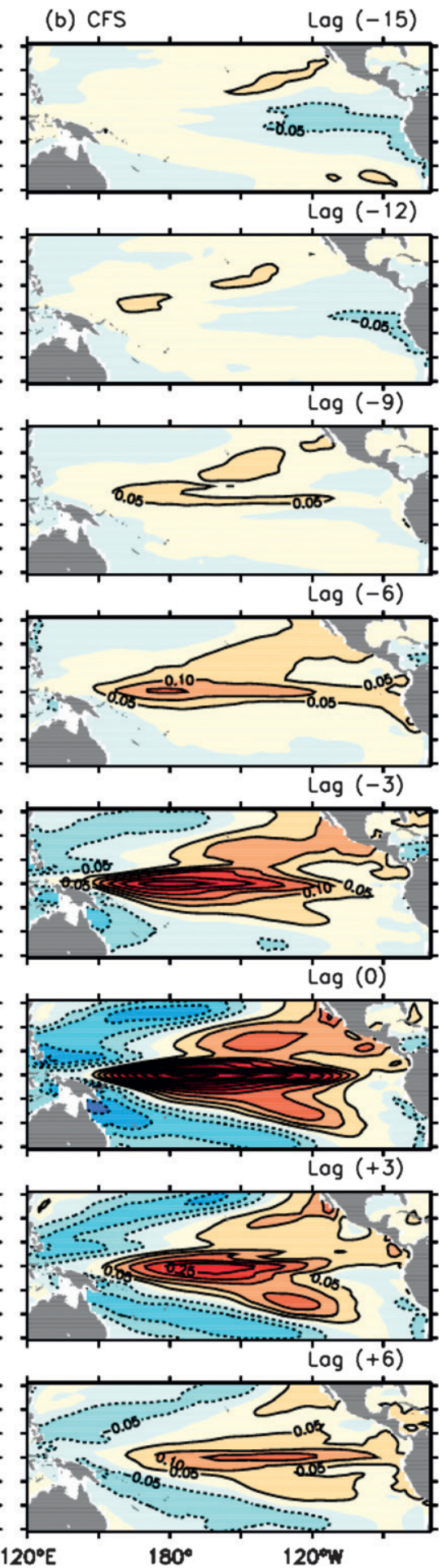

$120 \% \mathrm{w}$ onto the PCs of the EOFs to reveal their spatial patterns, which are displayed in Fig. 7.

The first two leading EOF modes obtained from the CFS simulations (Figs. 7c,d) are very similar to those obtained from the observations (Figs. 7a,b). The SLP anomalies regressed onto the PC of the first EOF mode (PC1; Figs. 7a,c) are characterized by a center over the region where the Aleutian low is located, indicating the 
(a) CP type jun-0378
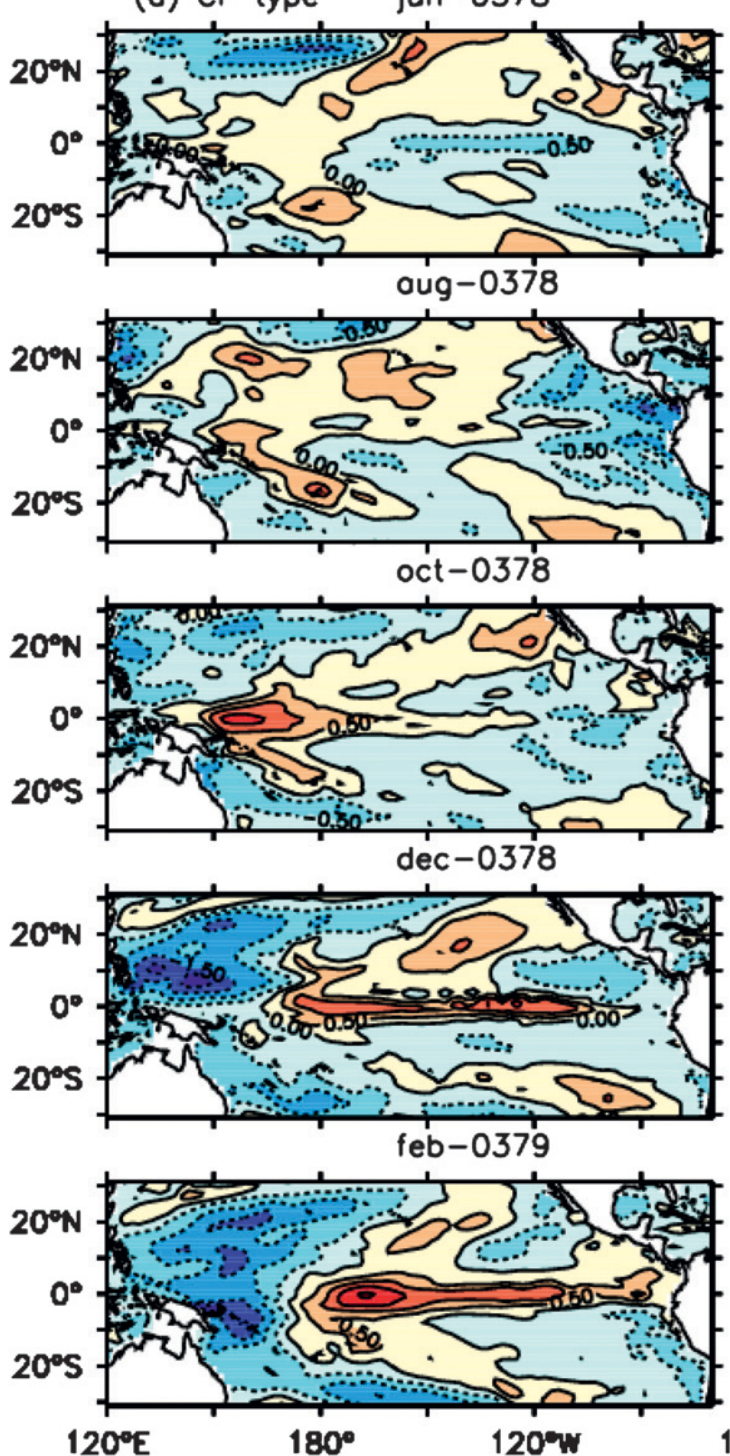

(b) EP type jun-0461
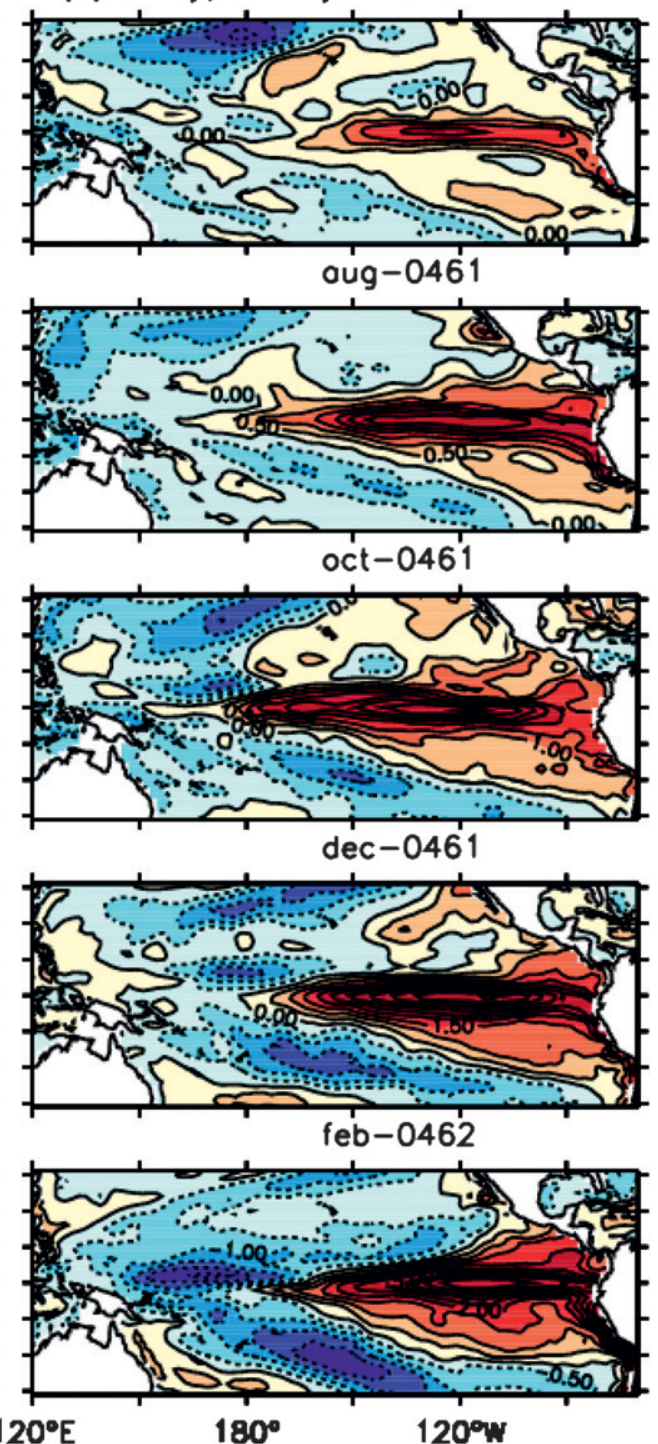

$180^{\circ}$

$120^{\circ} \mathrm{W}$

FIG. 5. The spatial evolution of tropical SST anomalies of two specific (a) CP (from June in 378 yr to February in $379 \mathrm{yr}$ ) and (b) EP (from June in $461 \mathrm{yr}$ to February in $462 \mathrm{yr}$ ) El Niño event selected using the CP and EP index from the CFS model.

first EOF mode represents variations in the strength of the Aleutian low. This mode has a tropical association that is characterized by an out-of-phase SLP variation between the eastern and western Pacific representing the Southern Oscillation. The regressed anomaly patterns for both the observed and simulated second EOF mode (Figs. 7b,d) are characterized by a meridional outof-phase variation between the subtropical Pacific region and higher latitudes that is called the NPO. As for the intensity of the NPO, maximum STDs (i.e., loading coefficients scaled by the square root of their corresponding eigenvalues) in both the northern and southern lobes of the NPO are not significantly different at a $95 \%$ level ( $f$ test) between the observations $(0.85$ and $0.82 \mathrm{mb}$, respectively) and CFS simulation (0.98 and $0.86 \mathrm{mb}$ ). It is, however, noted that differences appear in a horizontal elongation pattern of the southern lobe of the NPO between the observations and the CFS simulation. The observed NPO has a stronger meridional elongation, while the simulated NPO tends to be more zonally elongated. The southern lobe of the observed NPO extends into the deep tropics and reaches the equator, but the anomalies in the southern lobe of the simulated NPO decay quickly equatorward of $15^{\circ} \mathrm{N}$. 
(o) EP, CFS
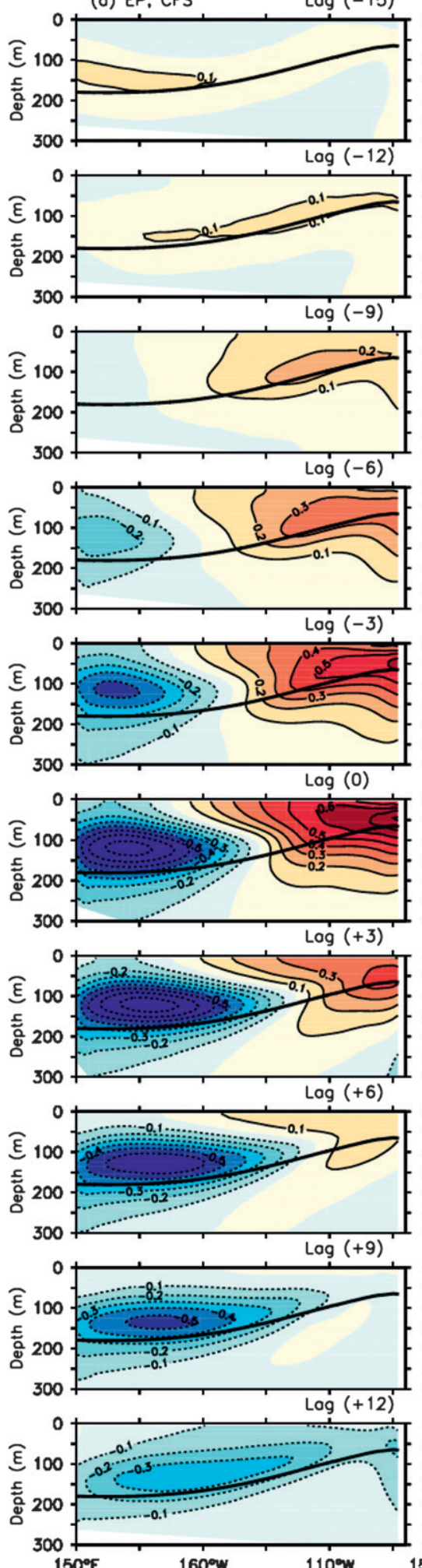

(b) CP, CFS
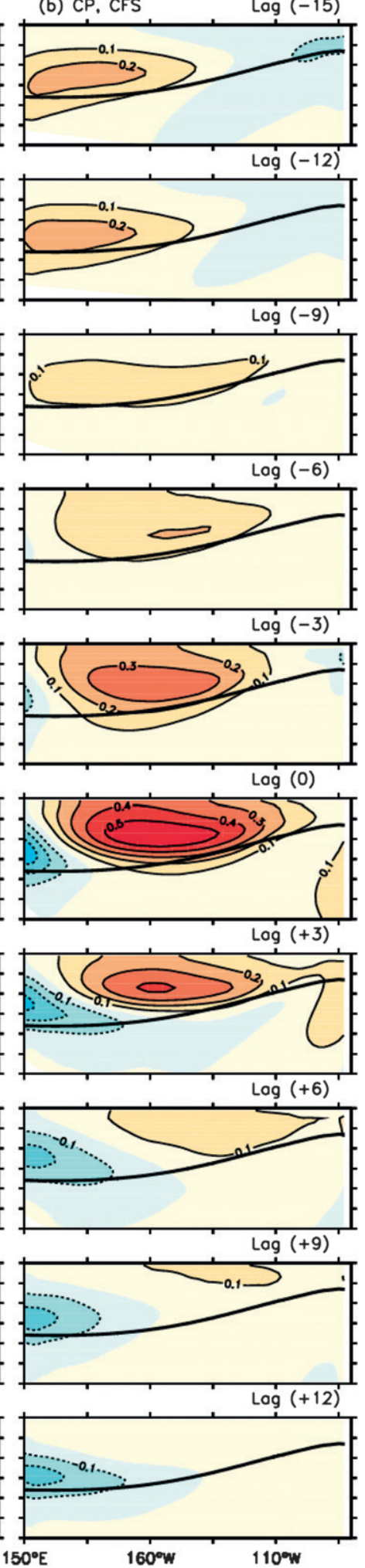

FIG. 6. Vertical cross sections of the lead-lag regression of the subsurface ocean temperature anomalies averaged between $5^{\circ} \mathrm{S}$ and $5^{\circ} \mathrm{N}$ in the Pacific onto the EP and $\mathrm{CP}$ indices. Climatological annual mean thermocline depth (thick black line), which is defined as $20^{\circ} \mathrm{C}$ isothermal depth, is also shown. Positive lags indicate that the indices lead subsurface ocean temperature anomalies. The zero contour lines are removed. 
(a) SLP PC1 and SLPA, OBS

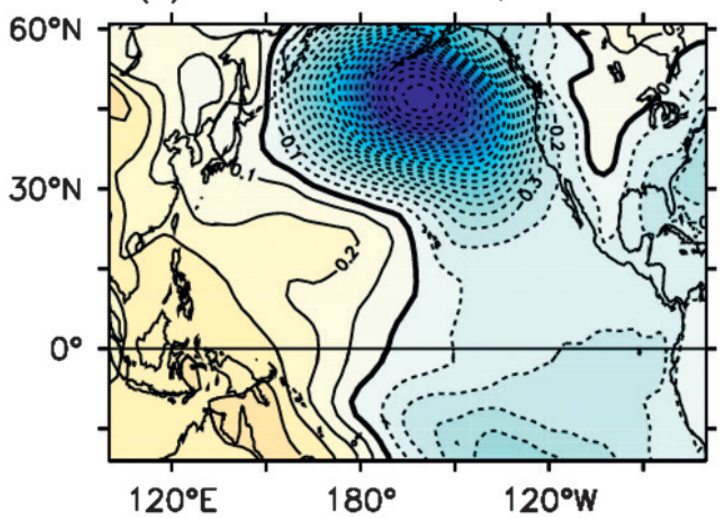

(c) SLP PC1 and SLPA, CFS

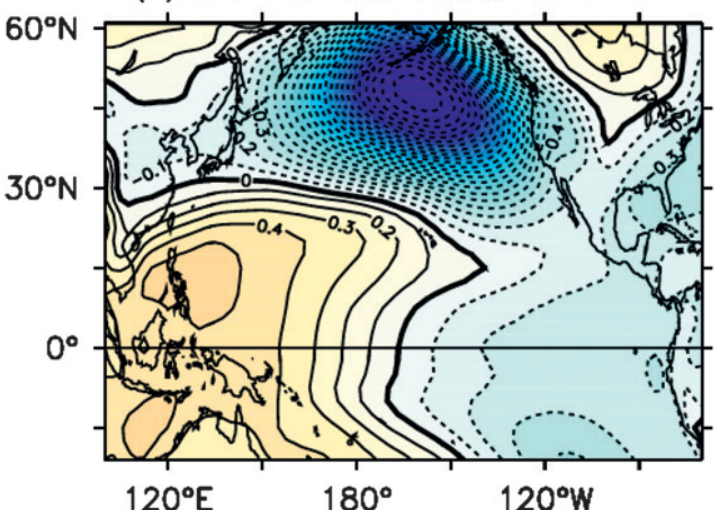

(b) SLP PC2 and SLPA

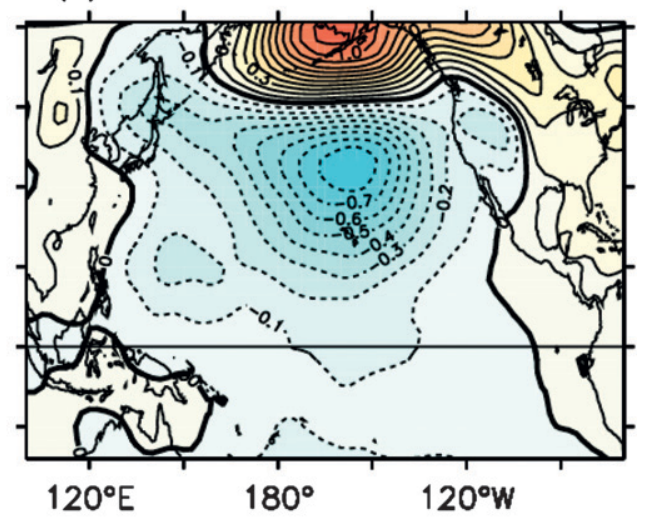

(d) SLP PC2 and SLPA

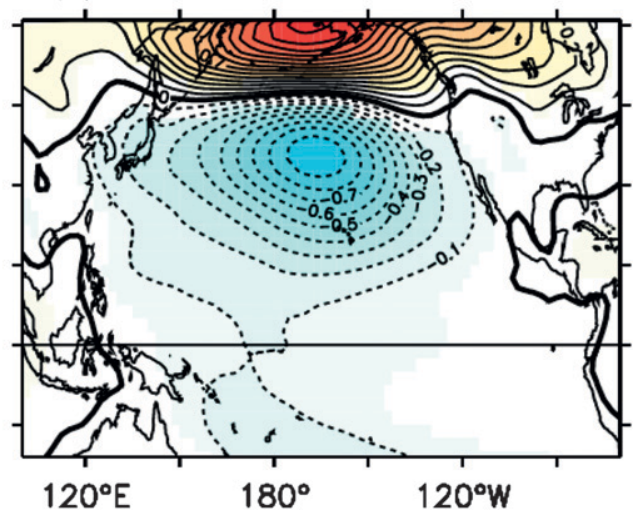

FIG. 7. The Pacific SLP anomalies regressed with the principal component of the (left) first and (right) second EOF modes from the (top) observations and (bottom) CFS model. The contour interval is $0.1(\mathrm{mb})$.

To examine the possible connection between NPO and ENSO, we regress Pacific SST anomalies onto the PC of the NPO, as shown in Fig. 8a for the observations. Near the peak phase of the NPO (from lags -2 to 0 ), SST anomalies are induced beneath the NPO, which include a band of positive SST anomalies extending from the northeastern Pacific to the tropical central Pacific, a zonal band of negative SST anomalies along $30^{\circ} \mathrm{N}$, and another band of positive SST anomalies along $50^{\circ} \mathrm{N}$. As explained in $\mathrm{Yu}$ and Kim (2011a, see their Fig. 8), the subtropical SST anomaly pattern is produced by the SLP anomalies associated with the NPO via surface heat fluxes. Also consistent with their explanation, the NPO-induced SST anomalies persist after the peak of the NPO, extend into the deep tropics (i.e., from lags 0 to +2$)$, likely due to the coupled SST-wind mode (e.g., Chiang and Vimont 2004; Vimont et al. 2009) feedbacks, and eventually develop into a CP ENSO (i.e., from lags +4 to +8$)$. The growth of the positive phase of the NPO is preceded by the decay of a La Niña event in the eastern Pacific (i.e., from lags -8 to -4 ), which was explained in Yu and Kim (2011a).
As for the CFS model (Fig. 8b), the evolution of the simulated SST anomalies regressed onto the NPO is, in general, similar to that of the observed. At the peak of the NPO, the CFS model reproduces the observed tripole SST anomaly pattern. However, the southernmost band of positive SST anomalies from the subtropical Pacific does not extend as far into the central Pacific as in the observations. This coincides with the location where the SLP anomalies of the southern lobe of the simulated NPO decay quickly (see Fig. 7d). Furthermore, from lags -2 to +4 , the SST anomalies to the south of the $15^{\circ} \mathrm{N}$ and in the northern tropics $\left(15^{\circ}-30^{\circ} \mathrm{N}\right)$ are not enhanced as they are in the observations, although, as mentioned previously, the intensity of the NPO in the CFS simulation is comparable to that in the observations. Therefore, the weak SST anomalies may be related with a model deficiency in simulating the coupled air-sea process in these regions. The coupled process in the CFS model will be further analyzed in the following paragraphs. In the CFS model, although the NPOregressed SST anomalies do occur in the equatorial central Pacific, they tend to be weaker than in the observations. 

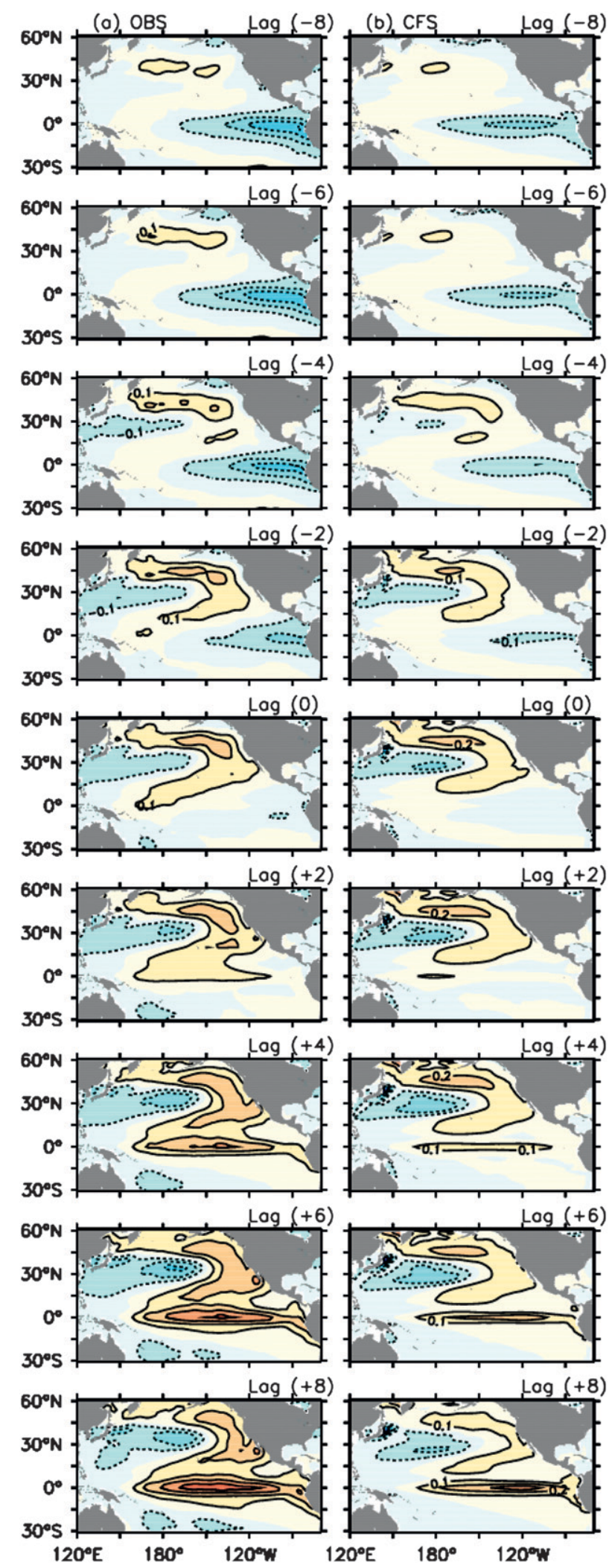

FIG. 8. (left) Observed and (right) simulated SST anomalies regressed with the second SLP mode from time lag -8 months to time lag +8 months. The contour intervals are $0.1^{\circ} \mathrm{C}$. The zero contour lines are removed. The positive lags denote the principal component leads the SST anomalies.

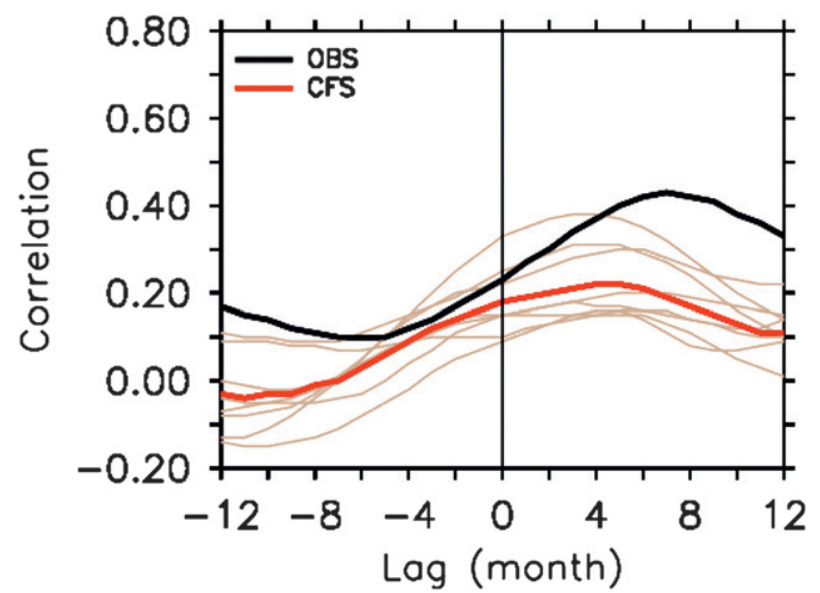

FIG. 9. Lead-lag correlation coefficients between the principal components of the second SLP mode and the CP indices from the observations (black line) and CFS model (red line). The analysis for eight 61-yr segments with the CFS model is indicated by light brown lines. Positive lags indicate that the principal component leads the CP-type ENSO.

Figure 8 suggests that the CFS model does simulate the observed extratropical forcing to the CP ENSO, but the forcing does not sustain its intensity as it extends into the tropics. This may be one reason why the CP ENSO is simulated with a weaker intensity in the CFS model.

To further examine the relationship between the NPO mode and the CP ENSO, we examine in Fig. 9 the leadlag correlation coefficients between the PC of the NPO and the $\mathrm{CP}$ indices (i.e., the PC of the leading EOF mode for the $\mathrm{CP}$ ENSO). In the observations, the largest correlation (0.43) occurs when the NPO leads the CP ENSO by seven months. For the CFS model, although it produces a lead-lag correlation evolution close to the observations, its largest correlation is only 0.22 , which occurs when the NPO leads the CP ENSO by five months. The smaller correlation in the CFS indicates a weaker influence of the extratropical SLP forcing on SST variability in the central tropical Pacific. The relatively small correlations in the CFS could be attributed to a much larger sample used (i.e., 500-yr monthly data in the CFS vs 61-yr monthly observational data) in that the observed correlation may be higher by chance. To examine this possibility, we repeated the lead-lag correlation analysis for eight 61-yr segments in the CFS simulation (light brown lines in Fig. 9). The correlations for the CFS are still consistently smaller than the observations, with the NPO leading the CP type by several months (varying from three to five months).

The relatively weak NPO influence on the tropics in the CFS model implies that the atmosphere-ocean coupling in the subtropical and tropical Pacific may be 

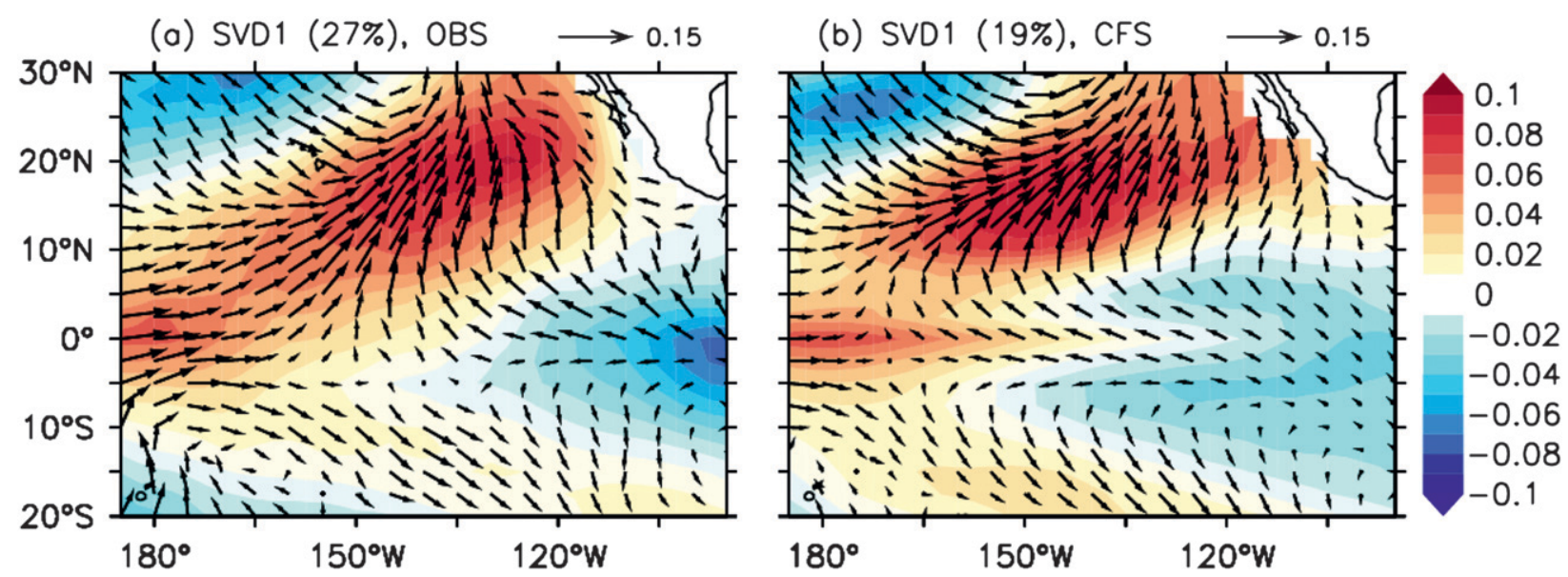

FIG. 10. Spatial patterns of the first mode of the SVD for SST (shadings) and wind (vectors) anomalies from (a) observations and (b) CFS model.

weaker in the model than in the observations. Vimont et al. $(2001,2003,2009)$ suggested a seasonal footprint mechanism to explain how midlatitude atmospheric variability can affect tropical SST variability via coupling in the subtropical Pacific. Alexander et al. (2010) examined the impacts of the seasonal footprinting mechanism on tropical SST variability using coupled model experiments and argued that the footprinting mechanism may force the Pacific meridional mode (MM; Chiang and Vimont 2004), which then acts to channel the extratropical influences into ENSO development. Therefore, we examine next the Pacific MM simulated in the CFS model to gauge the simulated strength of the atmosphere-ocean coupling in the subtropical and tropical Pacific.

The Pacific MM, which shares strong similarities with the Atlantic MM, is characterized by a north-south gradient of SST anomalies that is associated with the meridional movement of the intertropical convergence zone (ITCZ) and cross-ITCZ surface winds flowing toward the warmer SST regions with maximized over the largest meridional SST gradient. To obtain the MM, we use a singular value decomposition (SVD; Bretherton et al. 1992) analysis following Chiang and Vimont (2004). The SVD analysis is applied to the cross-covariance matrix between surface winds and SST anomalies in the region between $21^{\circ} \mathrm{S}-35^{\circ} \mathrm{N}$ and $175^{\circ}-95^{\circ} \mathrm{W}$. Prior to the SVD analysis, we subtract from the wind and SST anomalies their regressions on the cold tongue index (SST anomalies averaged over $6^{\circ} \mathrm{S}-6^{\circ} \mathrm{N}$ and $180^{\circ}-90^{\circ} \mathrm{W}$ ).

Figure 10 shows the spatial patterns of the first SVD mode for SST and wind anomalies from the observations and the CFS simulation. In the observations, subtropical SST anomalies associated with the SVD mode produce an anomalous meridional SST gradient, which induces anomalous meridional winds that extend deep into the tropical Pacific (Fig. 10a), thereby leading to well-formed westerly anomalies over the western equatorial Pacific region. This coupled SST-wind mode is similar to that obtained by Chiang and Vimont (2004). Following their terminology, the PCs of the SVD mode for SST and wind are also referred to here as the MM SST index and the MM wind index, respectively.

The simulated SVD mode (Fig. 10b) resembles closely the observed one. However, the SST anomalies in the simulated MM does not extend as far into the tropics as the observed, and thus the westerly wind anomalies over the western Pacific equator in the CFS model are not as strong as in the observations. Furthermore, the coupling between wind anomalies and SST anomalies in the model does not persist as long as in the observations as

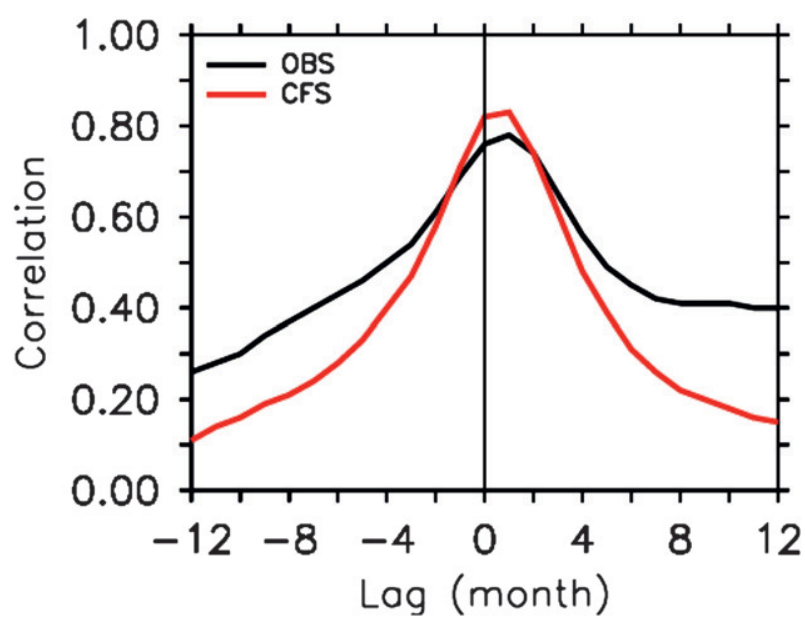

FIG. 11. Lead-lag correlation coefficients between MM wind index and MM SST index. Positive lags indicate that the MM wind index leads the MM SST index. 
revealed in Fig. 11, which displays the lead-lag correlations between the MM wind index and the MM SST index. In both the observations and simulation, the MM wind index leads the MM SST index by one month, which means that surface wind anomalies drive the SST variations in the tropical-extratropical Pacific. In the observations, the correlation is sustained to be larger than 0.4 for over 12 months after the MM wind peaks. However, in the CFS model, after the peak the correlation decreases more rapidly than in the observations. The SVD analysis presented in Figs. 10 and 11 indicates that, while the CFS model simulates the extratropical forcing and the Pacific MM in a way comparable to the observations, the simulated extratropical forcing does not extend far enough southward into the equatorial Pacific and the SST-wind coupling involved in the MM is not sustained as long as the observed.

In addition to the weaker-than-observed extratropical forcing, it is also possible that the weak CP ENSO in the CFS model is also a result of a weaker-than-observed zonal advection process in the equatorial Pacific. To explore this possibility, we perform a Bjerknes stability (BJ) index analysis ( $\mathrm{Jin}$ et al. 2006; Kim and Jin 2011a,b) to quantify how changes in ENSO SST anomalies are forced by three important positive feedback processes: the zonal advective feedback $\left(-u^{\prime} \partial \bar{T} / \partial x\right)$, the thermocline feedback $\left(-\bar{w} \partial T^{\prime} / \partial z\right)$, and the Ekman (upwelling) feedback $\left(-w^{\prime} \partial \bar{T} / \partial z\right)$. These feedbacks in the BJ index analysis are estimated based on the mean states of the tropical Pacific and a few other parameters that measure the sensitivity of the atmosphere to SST variations and the sensitivity of the ocean to surface wind variations.

Kim and Jin (2011b) demonstrated with 12 CMIP3 model simulations that simulated ENSO amplitude is well correlated with the ENSO stability as measured by the BJ index. They also suggested that the BJ index offers a way to quantify how each of the feedback processes contributes to the overall ENSO amplitude. The formulations for the BJ index calculation are provided in the appendix. Among these three positive feedback processes, the CP ENSO was suggested to rely primarily on the zonal advective feedback for its generation and the EP ENSO primarily on the "vertical" advection feedback (Kug et al. 2009; Yu et al. 2010), which includes both the thermocline and Ekman feedback processes.

In Table 1 we compare the three feedbacks calculated using output from the SODA reanalysis and the CFS simulation. The table shows that, in the SODA reanalysis, the thermocline feedback is the largest contributor, the zonal advective feedback is the second largest contributor, and the Ekman feedback is the smallest contributor to the growth of ENSO SST anomalies. In the CFS
TABLE 1. Magnitude $\left(\mathrm{yr}^{-1}\right)$ of three positive feedback terms in the BJ index computed from the SODA reanalysis and CFS simulation and their ratio (CFS/SODA): zonal advective feedback (ZA), Ekman feedback (EK), and thermocline feedback (TH).

\begin{tabular}{lccc}
\hline & SODA & CFS & Ratio (CFS/SODA) \\
\hline ZA & 0.52 & 0.08 & 0.15 \\
EK & 0.23 & 0.39 & 1.69 \\
TH & 1.28 & 0.59 & 0.46 \\
\hline
\end{tabular}

simulation, both the thermocline feedback and the zonal advective feedback are underestimated compared to those in the SODA reanalysis, while the Ekman feedback term is overestimated. Nevertheless, the thermocline feedback is still the largest contributor to the growth of ENSO SST anomalies in the CFS simulation. The combined ENSO stability due to the thermocline and Ekman feedbacks in the CFS simulation is about $65 \%$ of the combined value in the SODA reanalysis. However, the zonal advective feedback in the CFS simulation is only $15 \%$ of its magnitude in the SODA reanalysis. Therefore, Table 1 indicates that the CFS simulation captures $65 \%$ of the observed vertical advection feedback (i.e., the combination of the thermocline and Ekman feedbacks) estimated by the SODA reanalysis, but only about $15 \%$ of the zonal advective feedback in the reanalysis. These results are consistent with Fig. 2, which shows the CFS model produces an EP ENSO comparable to the observations but an unrealistically weak CP ENSO.

The weak zonal advective feedback in the CFS model can be partly attributed to the weak zonal SST gradients along the equator. The weak zonal SST gradients are related to the model warm bias in the eastern Pacific, as shown in Fig. 12a. The warm bias in the eastern Pacific can also be used to explain why the simulated NPO tends to be confined to the north of $15^{\circ} \mathrm{N}$ and why the SST-wind coupling associated with the MM is not sustained in the CFS model as long as in the observations. The simulated mean SLP around the warm bias region is lower than the observed (Fig. 12b). The negative SLP bias is particularly large south of $15^{\circ} \mathrm{N}$, which indicates that the subtropical high in the CFS model does not extend as far south as in the observations. This may be a reason why the southern lobe of the NPO, which is related to the variability of the subtropical high, does not extend far into the deep tropics. A weaker subtropical high may also weaken the mean trade winds in the same region. This wind bias can be seen in Fig. 12c, which displays the difference in climatological annual mean meridional surface winds between the CFS simulation and the observations. The largest wind bias in this figure appears on the equatorward side of $15^{\circ} \mathrm{N}$ and is oriented 

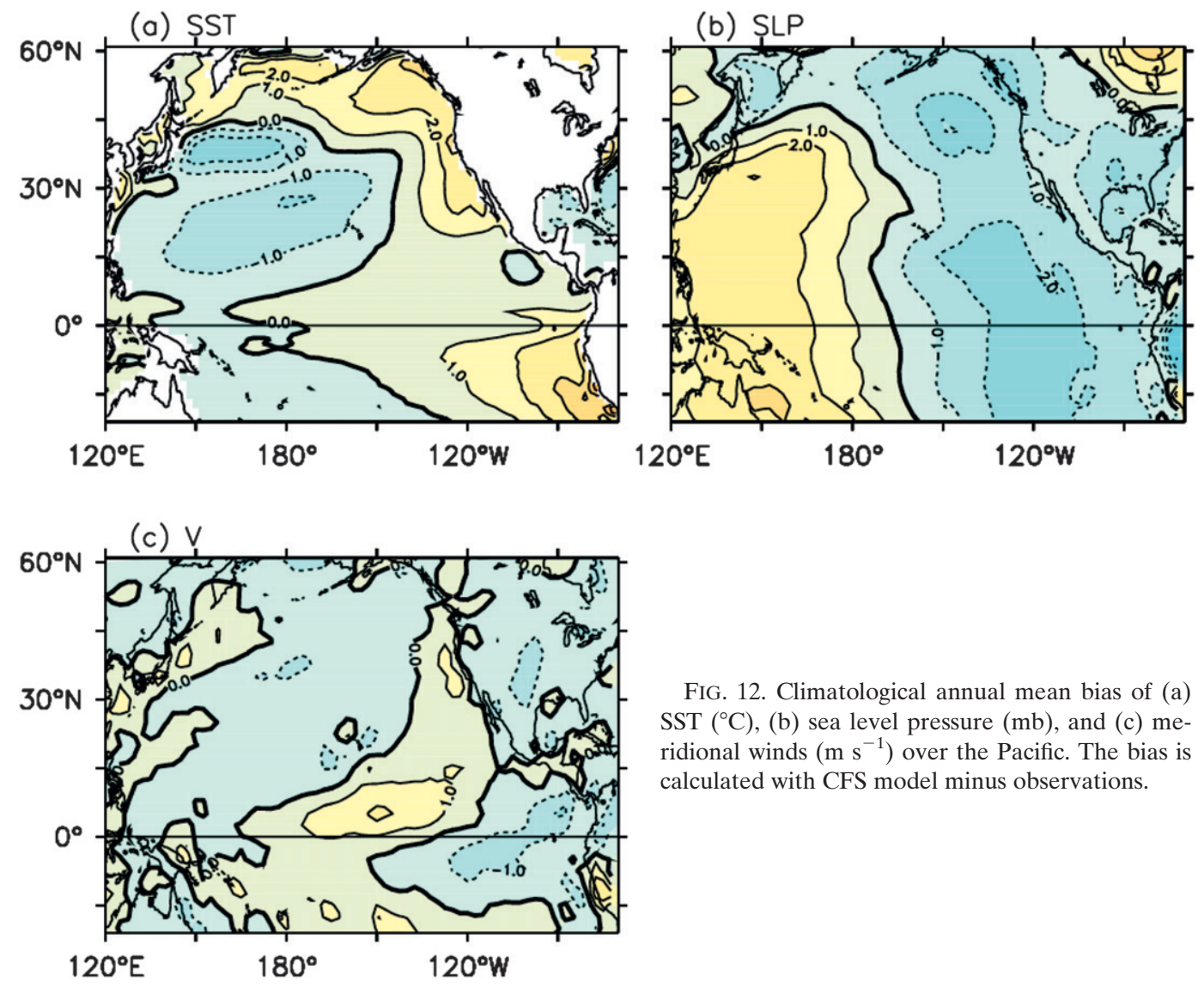

FIG. 12. Climatological annual mean bias of (a) SST $\left({ }^{\circ} \mathrm{C}\right)$, (b) sea level pressure (mb), and (c) meridional winds $\left(\mathrm{m} \mathrm{s}^{-1}\right)$ over the Pacific. The bias is calculated with CFS model minus observations.

from the northeastern Pacific to the central equatorial Pacific. This wind bias may be the reason why the SSTwind coupling in the northern subtropical Pacific and the tropics cannot be sustained long enough in the model, because the seasonal footprinting mechanism requires the anomalous winds to work against the climatological trade winds to maintain the NPO-induced subtropical SST variability through the wind-evaporation-SST (WES; Xie and Philander 1994) feedback. The unrealistically weak subtropical high simulated in the CFS may cause the WES feedback mechanism to work less efficiently. The warm biases in the northeastern Pacific (as well as in the southeastern Pacific) are a common CGCM deficiency due to underestimate in the amount and/or optical thickness of the marine stratocumulus clouds (e.g., Mechoso et al. 1995; Yu and Mechoso 1999a,b), and has been confirmed by $\mathrm{Hu}$ et al. (2011) to also occur in the CFS model. Hu et al. (2011) showed that the reduction of the low cloud errors can reduce the warm bias in the eastern Pacific. Therefore, the ability of coupled models in simulating the amount and/or the optical thickness of the marine stratocumulus can also be important to a realistic simulation of the CP ENSO.

\section{Summary and discussion}

We analyzed how well the two types of ENSO are simulated in the NCEP CFS model. It is concluded that the CFS model is able to simulate both the CP and EP types of ENSO with realistic spatial patterns and temporal evolution. The intensity of the EP ENSO is realistically simulated, but the simulated CP ENSO intensity is weak compared to the observations. Further analyses were performed to understand the possible causes of the underestimation of the CP ENSO in the CFS model. We noticed that the CFS does reproduce the NPO-forcing mechanism for the CP ENSO; however, the extratropical forcing decays too quickly into the tropics. The simulated NPO does not extend as far into the deep central equatorial Pacific as the observed. It is also found that the SST-wind coupling mechanism involved in the Pacific MM that helps spread the NPO-induced SST anomalies into the deep tropics over time is captured in the model, but the coupling is not sustained for as long as it is in the observations. As a result, a weaker central equatorial SST variability is induced by the NPO in the CFS model. In addition to the weak extratropical forcing 
in the model, the BJ index analysis indicates that the weaker CP ENSO in the CFS model is also partly due to unrealistically weak zonal advective feedback in the equatorial Pacific.

By analyzing the mean SST, SLP, and surface wind produced in the CFS model, we notice that the unrealistically weak extratropical forcing (and also zonal advective feedback) may be linked to the model deficiency in simulating the marine stratus clouds in the eastern Pacific. The underestimation of the amount and/or the optical thickness of these clouds may produce a warm bias in the region. In particular, the bias off the North American coast may limit the meridional extension of the southern lobe of the NPO as well as the efficiency of the SST-wind coupling in the northern Pacific and the deep tropics. While the impacts of the underestimation of Peruvian stratus on the climate of the eastern Pacific cold tongue-ITCZ complex have been extensively studied (e.g., Philander et al. 1996; Ma et al. 1996; Yu and Mechoso 1999a,b), the climate impacts of the underestimation of the North American stratus clouds have received relatively less attention. This study indicates that a realistic simulation of the stratus clouds in this region may be important to the realistic simulation of the $\mathrm{CP}$ ENSO and warrants further investigation.

Acknowledgments. This research was supported by NSF Grant ATM-0925396 and NOAA-MAPP Grant NA11OAR4310102.

\section{APPENDIX}

\section{Bjerknes Stability Index}

The BJ index can be formulated [see Kim and Jin (2011a) for a more detail explanation on the formulation of the $\mathrm{BJ}$ index] as the following:

$$
\mathrm{BJ}=\frac{R-\varepsilon}{2},
$$

where

$$
\begin{aligned}
R= & -\left(a_{1} \frac{\langle\Delta \bar{u}\rangle_{E}}{L_{x}}+a_{2} \frac{\langle\Delta \bar{v}\rangle_{E}}{L_{y}}\right)-\alpha_{s}+\mu_{a} \beta_{u}\left\langle-\frac{\partial \bar{T}}{\partial x}\right\rangle_{E} \\
& +\mu_{a} \beta_{w}\left\langle-\frac{\partial \bar{T}}{\partial z}\right\rangle_{E}+\mu_{a} \beta_{h}\left\langle\frac{\bar{w}}{H_{1}}\right\rangle_{E} a_{h} .
\end{aligned}
$$

The $u, v$, and $w$ denote the zonal, meridional, and vertical velocity anomalies, respectively; $T$ denotes anomalous temperature; and $Q$ denotes both net anomalous heat flux anomalies into the ocean from the atmosphere and diffusive processes. Variables with an overbar represent simulated climatological background state; $L_{x}$ and $L_{y}$ represent the longitudinal and latitudinal length of the eastern box, respectively; $a_{1}$ and $a_{2}$ are estimated using anomalous SSTs averaged zonally or meridionally at boundaries of an area-averaging box and area-averaged SST anomalies over the box; $H_{1}(=50 \mathrm{~m})$ is a mixed layer depth; $T_{\text {sub }}$, an anomalous subsurface temperature, and $\bar{w}$ are defined at the base of ocean mixed layer; and $\langle A\rangle$ denotes volume average quantities over the eastern region or western region of the equatorial Pacific basin, which are distinguished by the subscripts $E$ and $W$, respectively. Coefficients in the factor $R$ are computed from approximated balance equations, namely, $\langle Q\rangle=-\alpha_{s}\langle T\rangle_{E},\left\langle H(\bar{w}) T_{\text {sub }}\right\rangle_{E}=a_{h}\langle h\rangle_{E},\langle h\rangle_{E}-\langle h\rangle_{W}=\beta_{h}\left[\tau_{x}\right]$, $\langle H(\bar{w}) w\rangle_{E}=-\beta_{w}\left[\tau_{x}\right], \quad\langle u\rangle_{E}=\beta_{u}\left[\tau_{x}\right]+\beta_{\mathrm{uh}}\langle h\rangle_{w}$, and $\left[\tau_{x}\right]=\mu_{a}\langle T\rangle_{E}$, using the least squares regression method. Here, $H(x)$ is the step function to ensure that only the upward vertical motion affects surface temperature and $\left[\tau_{x}\right]$ denotes the zonally averaged wind stress anomalies.

Each term of the factor $R$, which collectively represents the Bjerknes positive feedback processes of tropical atmosphere-ocean interactions, from left to right, represents dynamic damping by mean currents, thermodynamic damping, zonal advective feedback, Ekman (upwelling) feedback, and thermocline feedback. All three feedbacks are positive, favoring SST perturbations that grow. The dynamical positive feedbacks depend on the characteristics of the background state and the atmospheric response sensitivity coefficients $\left(\mu_{a}\right)$ to ENSO SST anomalies, and the oceanic response sensitivity coefficients $\left(\beta_{h}, \beta_{u}\right.$, and $\left.\beta_{w}\right)$ to equatorial surface winds.

\section{REFERENCES}

Alexander, M. A., D. J. Vimont, P. Chang, and J. D. Scott, 2010: The impact of extratropical atmospheric variability on ENSO: Testing the seasonal footprinting mechanism using coupled model experiments. J. Climate, 23, 2885-2901.

Ashok, K., S. Behera, A. S. Rao, H. Weng, and T. Yamagata, 2007: El Niño Modoki and its teleconnection. J. Geophys. Res., 112, C11007, doi:10.1029/2006JC003798.

Battisti, D. S., and A. C. Hirst, 1989: Interannual variability in a tropical atmosphere-ocean model: Influence of the basic state, ocean geometry, and nonlinearity. J. Atmos. Sci., 46, 1687-1712.

Bretherton, C. S., C. Smith, and J. M. Wallace, 1992: An intercomparison of methods for finding coupled patterns in climate data. J. Climate, 5, 541-560.

Carton, J. A., and B. S. Giese, 2008: A reanalysis of ocean climate using Simple Ocean Data Assimilation (SODA). Mon. Wea. Rev., 136, 2999-3017.

Chiang, J. C., and D. Vimont, 2004: Analogous Pacific and Atlantic meridional modes of tropical atmosphere-ocean variability. J. Climate, 17, 4143-4158.

Hendon, H. H., E. Lim, G. Wang, O. Alves, and D. Hudson, 2009: Prospects for predicting two flavors of El Niño. Geophys. Res. Lett., 36, L19713, doi:10.1029/2009GL040100. 
Hu, Z.-Z., B. Huang, Y.-T. Hou, W. Wang, F. Yang, C. Stan, and E. K. Schneider, 2011: Sensitivity of tropical climate to lowlevel clouds in the NCEP climate forecast system. Climate Dyn., 36, 1795-1811, doi:10.1007/s00382-010-0797-z.

Jin, F.-F., 1997: An equatorial ocean recharge paradigm for ENSO. Part I: Conceptual model. J. Atmos. Sci., 54, 811-829.

—, and S.-I. An, 1999: Thermocline and zonal advective feedbacks within the equatorial ocean recharge oscillator model for ENSO. Geophys. Res. Lett., 26, 2989-2992.

—, S. T. Kim, and L. Bejarano, 2006: A coupled-stability index of ENSO. Geophys. Res. Lett., 33, L23708, doi:10.1029/ 2006 GL027221.

Kao, H.-Y., and J.-Y. Yu, 2009: Contrasting eastern Pacific and central Pacific types of El Niño. J. Climate, 22, 615-632.

Kim, H.-M., P. J. Webster, and J. A. Curry, 2009: Impact of shifting patterns of Pacific Ocean warming on north Atlantic tropical cyclones. Science, 325, 77-80.

Kim, S. T., and F.-F. Jin, 2011a: An ENSO stability analysis. Part I: Results from a hybrid coupled model. Climate Dyn., 36, 15931607, doi:10.1007/s00382-010-0796-0.

— from 20th- and 21st-century simulations of the CMIP3 models. Climate Dyn., 36, 1593-1607, doi:10.1007/s00382-010-0872-5.

Kistler, R., and Coauthors, 2001: The NCEP-NCAR 50-Year Reanalysis: Monthly means CD-ROM and documentation. Bull. Amer. Meteor. Soc., 82, 247-268.

Kug, J.-S., F.-F. Jin, and S.-I. An, 2009: Two types of El Niño events: Cold tongue El Niño and warm pool El Niño. J. Climate, 22, 1499-1515.

— J. Choi, S.-I. An, F.-F. Jin, and A. T. Wittenberg, 2010: Warm pool and cold tongue El Niño events as simulated by the GFDL 2.1 coupled GCM. J. Climate, 23, 1226-1239.

Larkin, N. K., and D. E. Harrison, 2005a: On the definition of El Niño and associated seasonal average U.S. weather anomalies. Geophys. Res. Lett., 32, L13705, doi:10.1029/ 2005 GL022738.

— cipitation anomalies during El Niño autumn and winter. Geophys. Res. Lett., 32, L16705, doi:10.1029/2005GL022860.

Ma, C.-C., C. R. Mechoso, A. W. Robertson, and A. Arakawa, 1996: Peruvian stratus clouds and the tropical Pacific circulation: A coupled ocean-atmosphere GCM study. J. Climate, 9, 1635-1645.

Mechoso, C. R., and Coauthors, 1995: The seasonal cycle over the tropical Pacific in general circulation models. Mon. Wea. Rev., 123, 2825-2838.

Mo, K., 2010: Interdecadal modulation of the impact of ENSO on precipitation and temperature over the United States. J. Climate, 23, 3639-3656.

Pacanowski, R. C., and S. M. Griffies, 1998: MOM 3.0 manual. NOAA/Geophysical Fluid Dynamics Laboratory, $668 \mathrm{pp}$.

Philander, S. G. H., D. Gu, D. Halpern, G. Lambert, N.-C. Lau, T. Li, and R. C. Pacanowski, 1996: Why the ITCZ is mostly north of the equator. J. Climate, 9, 2958-2972.

Rasmusson, E. M., and T. H. Carpenter, 1982: Variations in tropical sea surface temperature and surface wind fields associated with the Southern Oscillation/El Niño. Mon. Wea. Rev., 110, 354-384.
Rogers, J. C., 1981: The North Pacific Oscillation. J. Climatol., 1, $39-57$.

Schopf, P. S., and M. J. Suarez, 1988: Vacillations in a coupled ocean-atmosphere model. J. Atmos. Sci., 45, 549-566.

Smith, T. M., and R. W. Reynolds, 2003: Extended reconstruction of global sea surface temperatures based on COADS data (1854-1997). J. Climate, 16, 1495-1510.

Suarez, M. J., and P. S. Schopf, 1988: A delayed action oscillator for ENSO. J. Atmos. Sci., 45, 3283-3287.

Sun, F., and J.-Y. Yu, 2009: A 10-15-year modulation cycle of ENSO intensity. J. Climate, 22, 1718-1735.

Vimont, D. J., D. S. Battisti, and A. C. Hirst, 2001: Footprinting: A seasonal link between the mid-latitudes and tropics. Geophys. Res. Lett., 28, 3923-3926.

,$- \ldots$, and $—$ 2003: The seasonal footprinting mechanism in the CSIRO general circulation models. J. Climate, 16, 2653-2667.

$\ldots$, M. Alexander, and A. Fontaine, 2009: Midlatitude excitation of tropical variability in the Pacific: The role of thermodynamic coupling and seasonality. J. Climate, 22, 518-534.

Walker, G. T., and E. W. Bliss, 1932: World weather V. Mem. Roy. Meteor. Soc., 4, 53-84.

Wang, W., S. Saha, H.-L. Pan, S. Nadiga, and G. White, 2005: Simulation of ENSO in the new NCEP coupled forecast system model (CFS03). Mon. Wea. Rev., 133, 1574-1593.

Weng, H., S. K. Behera, and T. Yamagata, 2009: Anomalous winter climate conditions in the Pacific Rim during recent El Niño Modoki and El Niño events. Climate Dyn., 32, 663-674.

Xie, S.-P., and S. G. H. Philander, 1994: A coupled oceanatmosphere model of relevance to the ITCZ in the eastern Pacific. Tellus, 46A, 340-350.

Yeh, S.-W., J.-S. Kug, B. Dewitte, M.-H. Kwon, B. P. Kirtman, and F.-F. Jin, 2009: El Niño in a changing climate. Nature, 461, 511-514.

Yu, J.-Y., and C. R. Mechoso, 1999a: Links between annual variations of Peruvian stratocumulus clouds and of SST in the eastern equatorial Pacific. J. Climate, 12, 3305-3318.

— , and 1 1999b: A discussion on the errors in the surface heat fluxes simulated by a coupled GCM. J. Climate, 12, 416-426.

- and H.-Y. Kao, 2007: Decadal changes of ENSO persistence barrier in SST and ocean heat content indices: 1958-2001. J. Geophys. Res., 112, D13106, doi:10.1029/2006JD007654.

— Pacific El Niño. Geophys. Res. Lett., 37, L08706, doi:10.1029/ 2010GL042810.

$\longrightarrow$, and 2010b: Identification of central-Pacific and easternPacific types of El Niño in IPCC-AR4 models. Geophys. Res. Lett., 37, L15705, doi:10.1029/2010GL044082.

— level pressure variations and the central Pacific and eastern Pacific types of ENSO. J. Climate, 24, 708-720.

, and - , 2011b: Reversed spatial asymmetries between El Niño and La Niña in CMIP3 models. J. Climate, 24, 5423-5434.

- H.-Y. Kao, and T. Lee, 2010: Subtropics-related interannual sea surface temperature variability in the equatorial central Pacific. J. Climate, 23, 2869-2884.

Zhang, Q., A. Kumar, Y. Xue, W. Wang, and F.-F. Jin, 2007: Analysis of ENSO cycle in NCEP coupled forecast model. J. Climate, 20, 1265-1284. 